\title{
Oxidation of multi-walled carbon nanotubes in acidic and basic Piranha mixture
}

\author{
Tariq Al Mgheer and Firas H Abdulrazzak* \\ College of Medicine, University of Babylon, Iraq \\ *College of Education for Pure Sciences, University of Diyala, Iraq
}

\begin{abstract}
Multi-walled carbon nanotubes MWNTs were oxidized by using acid and base Piranha reagent. The acid reagent consists of mixture solution 3:1 $\mathrm{H}_{2} \mathrm{SO}_{4}: \mathrm{H}_{2} \mathrm{O}_{2}$, while the base reagent was $\mathrm{NH}_{4} \mathrm{OH}: \mathrm{H}_{2} \mathrm{O}_{2}$. We will discuss our results by using XRD diffraction to also study the effect of oxidizing agents on the surface by measuring the surface area. The ratios of carboxylic groups were discus by making back titration with $0.5 \mathrm{~N} \mathrm{HCl}$. The results show a shift in the main of XRD peaks in addition to increasing the agglomerates which causing reduces in the surface area. The effect of oxidizing agents was testing adsorption $40 \mathrm{ppm}$ of Cobalamin which shows enhance with oxidized MWNTs as compare with pristine MWNTs. In addition to MWNTs which treated with acid piranha was more activity to adsorbed Cobalamin than base piranha.
\end{abstract}

\section{Introduction}

Since Iijima published [1] the first paper of carbon nanotubes CNTs huge amount of attentions were focussed in nanomaterial. The interesting in this nanomaterial related to many reasons, one of them represent by physiochemical properties of carbon nanotubes CNTs, such as mechanisms [2], thermal [3], electrical [4], and optoelectronic properties [5]. The other reasons related to many of various applications such as technologies of water purification [6], synthesis of composites [7], hydrogen storage media [8], hydrogen production [9]. The carbon nanotubes are widely used in inorganic chemistry when coordination many legends in complex compound such as Vaska's compound [10] with metals. The nanotube can be considered as a legend and functioned with respect to the central metal atom, in coordination complex. Mostly CNTs treated with different techniques and materials before use it which related to abilities the surface of CNTs Firmly resist different Redox reagents which prevent Association with the various components. The oxidation process commonly used for purification [9] and activation the CNTs [11]. The treatments of CNTs either by wet chemical methods [12], photooxidation [13], or gas phase treatment [14] has commonly used to purify and activation of the graphitic network. The Piranha mixture [15] one of the reagents that used for this purpose, which done in acidic solution [acidic piranha $\left(\mathrm{H}_{2} \mathrm{SO}_{4} / \mathrm{H}_{2} \mathrm{O}_{2}\right)$ ], or basic solution [basic piranha $\left(\mathrm{NH}_{4} \mathrm{OH} / \mathrm{H}_{2} \mathrm{O}\right)$ ) . A typical piranha mixture is 3 parts of acid or base with 1 part of hydrogen peroxide solution; other methods may use different ratios of them. Ziegler et al. [16] reported that piranha can be used to cut the tubes of SWNTs under specific and controlled conditions. Datsyuk et al. [17] published comparative studies for oxidant the MWNTs with $\left(\mathrm{H}_{2} \mathrm{SO}_{4} / \mathrm{H}_{2} \mathrm{O}_{2}\right)$ and $\left(\mathrm{NH}_{4} \mathrm{OH} / \mathrm{H}_{2} \mathrm{O}_{2}\right)$ as well as many oxidant materials. The $\left(\mathrm{H}_{2} \mathrm{SO}_{4} / \mathrm{H}_{2} \mathrm{O}_{2}\right)$ showed much lower oxygen content compared to nitric acid oxidation and the absence of added defects on the graphite surface, while $\left(\mathrm{NH}_{4} \mathrm{OH} / \mathrm{H}_{2} \mathrm{O}_{2}\right.$ complete removal of disordered carbon of the MWNT specimens. Das et al. [18] reported that $\mathrm{H}_{2} \mathrm{O}_{2}$ used with different acid and basic compound in purifying and functionalities pristine MWCNTs. Das et al. found that $\mathrm{HCl}$ with $\mathrm{H}_{2} \mathrm{O}_{2}$ shows more activity than $\mathrm{HCl}$ and $\mathrm{KOH}$ with $\mathrm{H}_{2} \mathrm{O}_{2}$ in the purification process. Kim et al. [19] have treated MWNTs with an $\mathrm{NH}_{4} \mathrm{OH} / \mathrm{H}_{2} \mathrm{O}_{2}$ mixture and showed that the resulting composite with epoxy as matrix had enhanced electrical conductivity due to the minor damages of the graphitic sidewalks. In our earlier work [20] binary composites $\mathrm{TiO}_{2} / \mathrm{CNTs}$ were analyzed by Raman spectroscopy and X-ray diffraction the work include using SWNTs and MWNTs with $\mathrm{TiO}_{2}$. The analyzing of binary composite $\mathrm{TiO}_{2} / \mathrm{CNT}$ deals with the effect of SWNTs and MWNTs on the structure of $\mathrm{TiO}_{2}$ and in the activity of binary materials. In these work multiwalled carbon nanotubes MWNTs treated with the piranha reagent in two conditions acidic and basic solution. The effect of oxidation by reagent were characterized by $\mathrm{X}$-ray analysis and measuring the surface area with measuring the carboxylic groups by titration methods. The $\mathrm{H}_{2} \mathrm{O}_{2}$ existed in two solutions as complementary materials for reagent with $\mathrm{H}_{2} \mathrm{SO}_{4}$ (acid solution) or $\mathrm{NH}_{4} \mathrm{OH}$ (basic solution). The activities of oxidation were tested in adsorption of $40 \mathrm{ppm}$ Cobalamin at room temperature and makes comparisons with MWNT without oxidant.

\section{Experimental}

\section{Materials}

MWNTs, used in this study were purchased from (Aldrich). According to the product specifications, the compound was fabricated by chemical vapor deposition method. The MWNTs $95 \%$ carbon nanotubes with mode diameter $5.5 \mathrm{~nm}$. Hydrogen peroxide $(30 \%)$ from Barcelona-spain. Sulfuric acid (99\%) from Merck, Germany and ammonium hydroxide were supplied from Sigma Aldrich.

Correspondence to: Firas $\mathrm{H}$ Abdulrazzak, College of Education for Pure Sciences, University of Diyala, Iraq; E-mail: firas_habeb2000@yahoo.com

Key words: carbon nanotubes, piranha reagent, xrd diffrection, adsorption

Received: June 08, 2016; Accepted: June 22, 2016; Published: June 26, 2016 


\section{Method of oxidation MWNT}

$15 \mathrm{ml}$ of hydrogen peroxide added very slowly to $45 \mathrm{ml}$ of concentrated $\mathrm{H}_{2} \mathrm{SO}_{4}$ then allowed to cool before use. $100 \mathrm{mg}$ of multiwalled carbon nanotubes added into $60 \mathrm{ml} \mathrm{H}_{2} \mathrm{SO}_{4} / \mathrm{H}_{2} \mathrm{O}_{2}$ mixture, then stirred for 6 hours at room temperature. The powders were rinsed several times with deionized water and $0.1 \mathrm{M} \mathrm{NaOH}$ until the $\mathrm{pH}$ value reached around 7 . After drying, MWNT where heat treatment at $100^{\circ} \mathrm{C}$ over night by the oven. The product from these steps was referring to it by acid piranha +MWNT. The second sample MWNTs added into $\mathrm{NH}_{4} \mathrm{OH} / \mathrm{H}_{2} \mathrm{O}_{2}(45: 15)$ mixture to use the same condition of oxidation and washing the MWNT with deionized water and $0.1 \mathrm{M} \mathrm{HCl}$ neutralized the solution around 7 units. After that, complete the washing and during than thermal treatment for the sample which labeled base piranha + MWNT. The process causing produces many active sites on the surface of MWNTs as shown in Figure 1.

\section{Experimental}

\section{XRD analysis}

XRD measurements carried out to check the effect of piranha reagent within the structure of MWNTs. The peak at $25.52^{\circ}$ represents the characteristic graphitic peak arising due to the presence of the tubular structure of the carbon atoms in the sample with (002) planes (Figure 2). The peak near $43.2^{\circ}$ is attributed to the (101) planes of the nanotube structure [21-22]. The oxidized carbon nanotubes by acidic and basic piranha reagent showed two peaks at $14.3^{\circ}$ and $16.8^{\circ}$ which related to remaining salts which produces from acid and base solution for washing [23]. From Figure 3 the first two peaks before $20^{\circ}$ can be

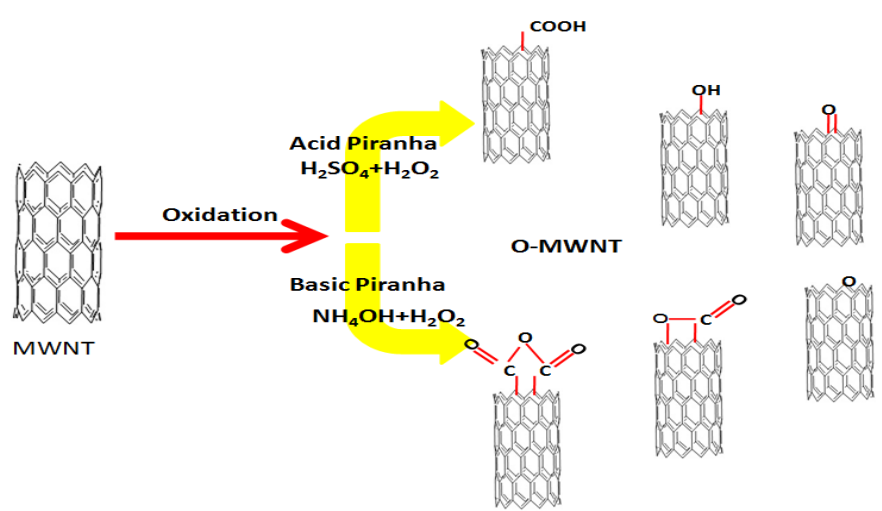

Figure 1. Schematic of the process of reaction MWNTs with acid and base Piranha.

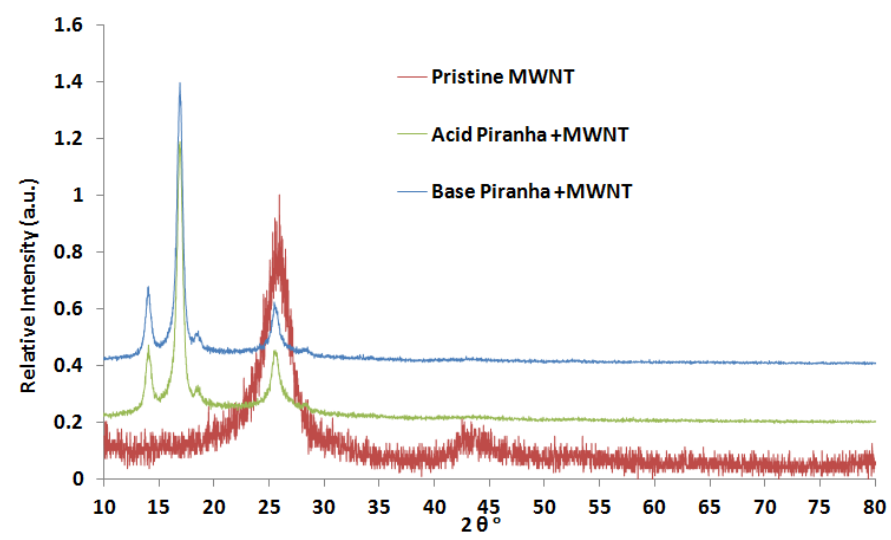

Figure 2. X-Ray diffraction patterns for pristine and oxidized MWNTs by acid and base piranha reagents. related to remaining carbon [24-25] which oxidized by reagent which shows more intensity for MWNTs that oxidized by acid piranha as compare with base piranha.

Figure 4, shows that first main peaks of MWNTs at $25.8^{\circ}$ reduced in intensity about four times with acid piranha and five times with base piranha while the shift of the peaks reach to $0.5^{\circ}$. This behavior could be related to increase the particle size of oxidized MWNTs by agglomerates the groups of MWNTs which can calculate by Scherer equation (Figures 5 and 6 ).

The second main peaks at $43.3^{\circ}$ completely removed when oxidized by piranha reagents which may relate to increase the interference between tubular structures when produce oxidation groups. These phenomena enhance the aggregates of MWNTs causing increase the size of groups

$\mathrm{X}$-ray diffraction patterns were used to determine the crystalline size (d) estimated by line broadening measurements in the DebyeScherrer equation [26]:

$$
\mathrm{d}=\mathrm{K} \lambda / \beta \cos \theta
$$

Where $\lambda$ is the $\mathrm{X}$-ray wavelength in nanometers $(\mathrm{nm})$ equal to $(0.15405 \mathrm{~nm}), \beta$ is the peak width of the diffraction peak profile at half the maximum height FWHM resulting from small crystallite size in radians, and $\mathrm{K}$ is a constant related to the crystallite shape mostly equal to 0.9 .

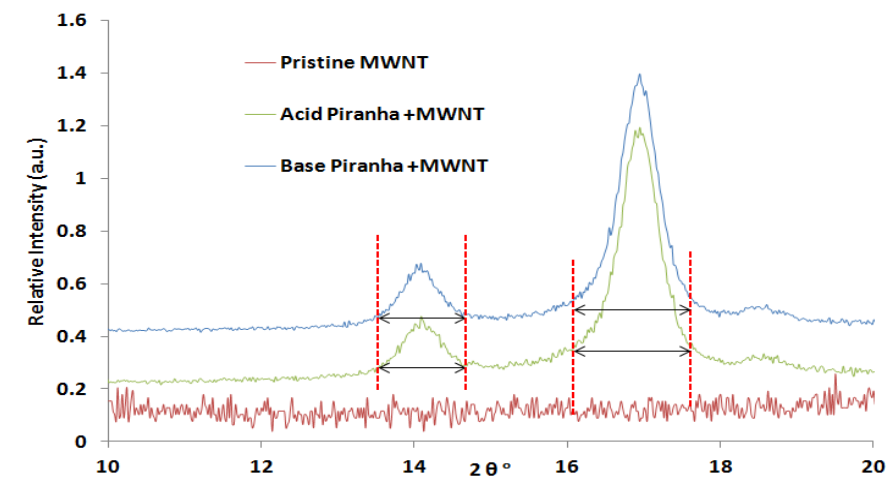

Figure 3. X-ray diffraction patterns for pristine and oxidized MWNTs by acid and base piranha reagents from $2 \theta=10-20^{\circ}$.

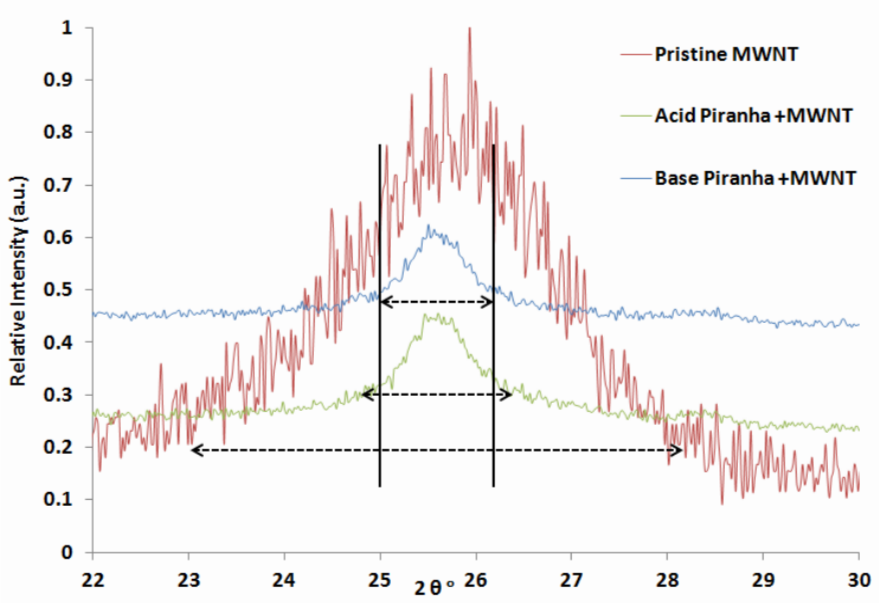

Figure 4. X-Ray diffraction patterns to compare the effect of oxidant reagents for $2 \theta=22$ $30^{\circ}$. 


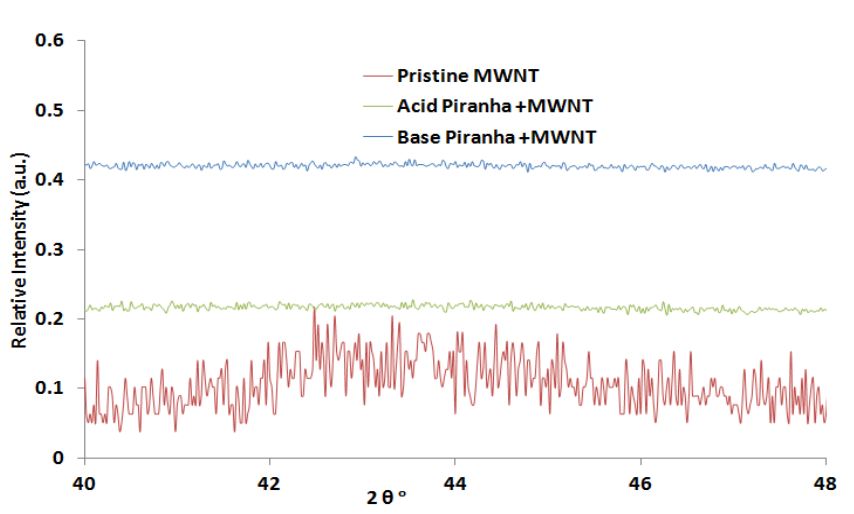

Figure 5. X-ray diffraction patterns for pristine and oxidized MWNTs from $2 \theta=40^{\circ}$ to $2 \theta=48^{\circ}$.

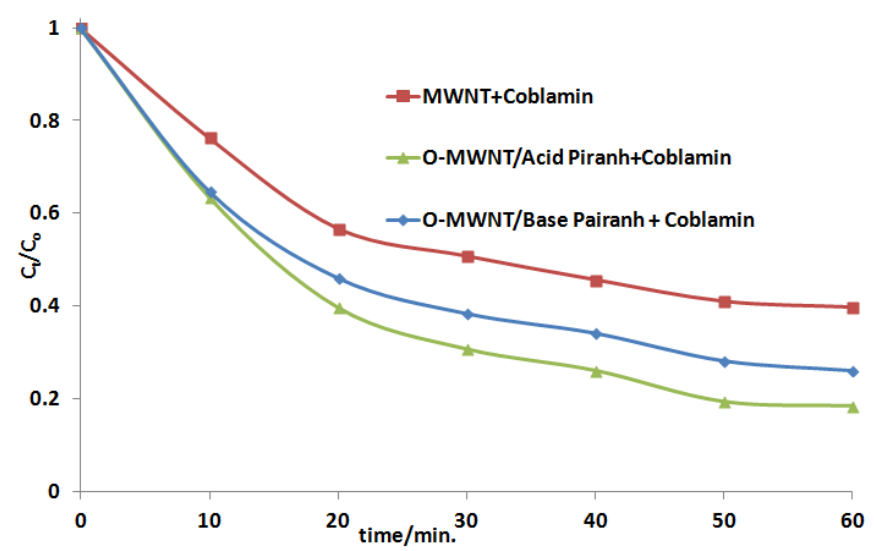

Figure 6. The values of $\mathrm{C}_{\mathrm{t}} / \mathrm{C}_{\mathrm{o}}$ for the adsorption of $40 \mathrm{ppm}$ of Cobalamin by $50 \mathrm{mg} / 100 \mathrm{~mL}$ of pristine and oxidized MWNTs by acid and base piranha at $298.15 \mathrm{~K}$.

\section{Titration analysis}

The titration analysis was done as explained by Datsyuk et. al. [27] when determine the ratios of carboxylic groups. The method depends on measuring the amount $(\mathrm{m} \mathrm{mol})$ of carboxylic group on the surface of gram MWNTs. Briefly, the pristine and oxidized MWNTs (50 mg) were dispersed in $50 \mathrm{ml}$ of $0.05 \mathrm{~N}$ sodium hydroxide with string for $24 \mathrm{~h}$ to complete the equilibrium between carboxylic and hydroxyl groups. After that, non-reactant sodium hydroxide was calculated by back titration with $0.05 \mathrm{~N}$ of hydrochloric acid. The results show that effect of acid piranha reagent to create carboxylic groups were more

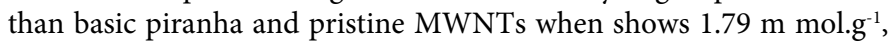
$1.5 \mathrm{~m} \mathrm{mol.g}{ }^{-1}$ and $1.4 \mathrm{~m} \mathrm{mol.g} \mathrm{g}^{-1}$ respectively.

From reported results in Table 1, the particle size of oxidized MWNTs increase to more than double values as compared with pristine MWNTs. Increase the practical size effect on the value of surface area for the materials after treatment with oxidized reagent, which was more for base piranha than acid piranha. At the same time the results of titration show that small value of carboxylic groups with MWNTs which oxidized with base piranha. The reduce in carboxylic groups related to creating a base group on the surface of MWNTs which enhance the agglomerations and reduces the surface area.

\section{Measuring the activity}

The activity of the new changing surface was tested by adsorption [21] Cobalamin $\left(\mathrm{C}_{63} \mathrm{H}_{88} \mathrm{CoN}_{14} \mathrm{P}\right)$, which is vitamin $\mathrm{B} 12$, as a complex compound of an organometallic species with a cobalt atom in the Corrine ring [28]. The typical adsorption experiments of $40 \mathrm{ppm}$ Cobalamin molecules with $0.05 \mathrm{~g}$ of pristine and oxidized MWNTs in aqueous phases. The $\mathrm{pH}$ equal to 7.8 at $298.15 \mathrm{~K}$ by adding $1 \mathrm{~N} \mathrm{NaOH}$ or $\mathrm{HCl}$, with using magnetic mixer at $475 \mathrm{rpm}$. The required amount of the adsorbent where suspend in $100 \mathrm{~cm}^{3}$ of an aqueous solution of Cobalamin; in various times $2 \mathrm{ml}$ taken from the reaction vessel, and filtered to remove the particles by centrifuge at 4,000 rpm for 10 minutes in an $800 \mathrm{~B}$ centrifuge. The Cobalamin absorbance was measured at $550 \mathrm{~nm}$, using a Shimadzu Cary 100Bio UV - visible spectrophotometer.

The adsorption experiments of the Cobalamin solutions follow the pseudo first-order kinetics with respect to the concentration of dyestuff in the bulk solution $\left(\mathrm{C}_{0}\right)$ :

$$
\ln \left(\mathrm{C}_{0} / \mathrm{C}_{\mathrm{t}}\right)=\mathrm{k}_{1}^{*} \mathrm{t}
$$

Where $\mathrm{C}_{0}$ refer to the initial concentration in the bulk solution before starting the adsorption process, $\mathrm{C}$ refers to concentration of Cobalamin after $\mathrm{t}$ min of adsorption. The $\mathrm{k}_{1}$ is the adsorption rate constant. A plot of $\ln \left(\mathrm{C}_{0} / \mathrm{C}\right)$ versus $t$ for Cobalamin adsorption with pristine and oxidized MWNTs with acid and basic reagent is presented in Figure 7. The value of $k_{1}$ can be obtained directly from the slope of the respective linear curves in the plot which listed in Table 1

The synergy factor ( $R$ ) [29] is defined as the following equations:

$$
\mathrm{R}=\mathrm{k}(\mathrm{O}-\mathrm{MWNT}) / \mathrm{k} \text { (pristine-MWNT) }
$$

When $\mathrm{k}(\mathrm{O}-\mathrm{MWNT}), \mathrm{k}$ (pristine-MWNT) refer to the adsorption rate constant for remove Cobalamin in exist of oxidized and pristine MWNTs respectively.

Table 1. The value of FWHM for characterized peak $\left(2 \theta \approx 25^{\circ}\right)$ and the particle size with surface area for pristine and oxidized MWNTs.

\begin{tabular}{|l|c|c|c|c|}
\hline Sample & $\mathbf{2}^{\circ}$ & $\mathbf{F W H M}$ & $\mathbf{D}_{\mathbf{0 0 2}}$ & $\left.\mathbf{S}_{\text {BET }} \mathbf{m}^{\mathbf{2}} / \mathbf{g}\right)$ \\
\hline Pristine MWNT & 25.52 & 2.2630 & 3.58 & 282 \\
\hline Acid Piranha+ MWNT & 25.65 & 0.8494 & 9.55 & 175 \\
\hline Base Piranha+ MWNT & 25.63 & 0.8033 & 10.09 & 146 \\
\hline
\end{tabular}

Table 2. The value of rate adsorption and compare for the synergy factor for adsorption process of Cobalamin by pristine e and oxidized MWNTs.

\begin{tabular}{|l|c|c|}
\hline Sample & $\mathrm{K}\left(\mathrm{s}^{-1}\right)$ & $\mathrm{R}$ \\
\hline Pristine MWNT & 0.0183 & 1 \\
\hline Acid Piranha+ MWNT & 0.0259 & 1.41 \\
\hline Base Piranha+ MWNT & 0.0331 & 1.80 \\
\hline
\end{tabular}

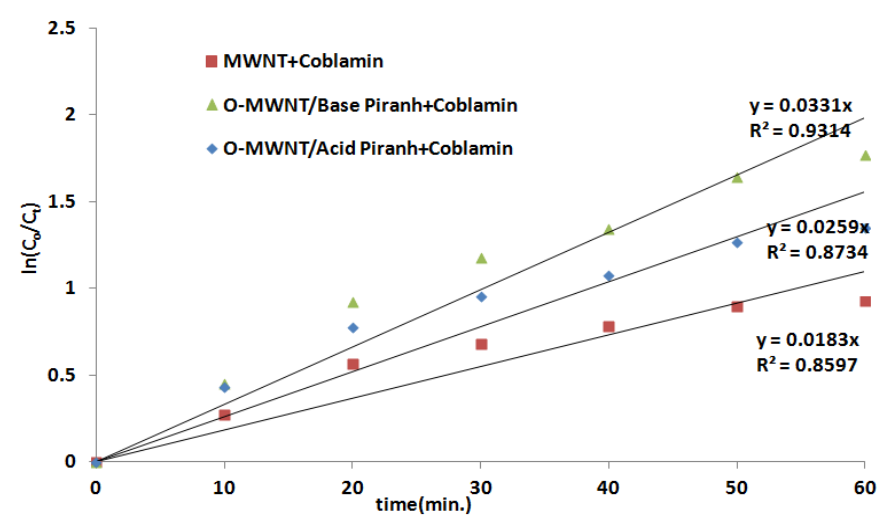

Figure 7. Rate constant for pristine and oxidized ( $0.05 \mathrm{~g})$ MWNTs with $40 \mathrm{ppm}$ Cobalamin at $298.15 \mathrm{~K}$. 
The results showed that MWNTs after the oxidation succeed in adsorption the Cobalamin

$$
\text { O-MWNT (acid piranha) > O-MWNT(base piranha) }>\text { MWNT }
$$

\section{Conclusion}

Chemical oxidations of MWNTs with acid and base piranha reagents were studied. The reference sample was pristine Aldrich MWNTs which contains very low amount of graphite nanoparticles without any functionalized oxygen groups. The oxidative reagents used were acidic piranha solution $\left(\mathrm{H}_{2} \mathrm{SO}_{4} / \mathrm{H}_{2} \mathrm{O}_{2}\right)$ and basic piranha solution $\left(\mathrm{NH}_{4} \mathrm{OH} / \mathrm{H}_{2} \mathrm{O}_{2}\right)$. After each treatment, the functionalization yield, namely the density of carboxyl and hydroxyl functional groups in the graphitic network, was quantified by titration measurements. The results show that acidic piranha was succeeding in the creation of many groups of carboxylic acid, which was more than basic piranha and pristine MWNTs. The effect of oxidation enhances the adsorption of Cobalamin by creating more functional groups on the surface and reduce the agglomeration. For that XRD analysis, which refers to agglomeration and ratios of functional groups by titration explained preference the activity of acidic piranha as compare with base and pristine MWNTs.

\section{References}

1. Iijima S (1991) Helical microtubules of graphitic carbon. Nature 354: 56-58.

2. Vigolo B, Pénicaud A, Coulon C, Sauder C, Pailler R, et al. (2000) Macroscopic fibers and ribbons of oriented carbon nanotubes. Science 290: 1331-1334. [Crossref]

3. Itkis ME, Borondics F, Yu A, Haddon RC (2007) Thermal conductivity measurements of semitransparent single-walled carbon nanotube films by a bolometric technique. Nano Lett 7: 900-904. [Crossref]

4. Liu J, Rinzler AG, Dai H, Hafner JH, Bradley RK, et al. (1998) Fullerene pipes. Science 280: $1253-1256$

5. Whitby RLD, Fukuda T, Maekawa T, James SL, Mikhalovsky SV(2008) Geometric control and tuneable pore size distribution of buckypaper and buckydiscs. Carbon 46 : 949-956.

6. Ali ME, Das R, Maamor A, Hamid SBA (2014) Multifunctional carbon nanotubes (CNTs): a new dimension in environmental remediation. Advanced Materials Research 832: 328-332.

7. Parveen S, Rana, R Fangueiro( 2013) A review on nanomaterial dispersion, microstructure, and mechanical properties of carbon nanotube and nanofiber reinforced cementitious composites. Journal of Nanomaterials.

8. Sahaym U, Norton MG (2008) Advances in the application of nanotechnology in enabling a hydrogen economy. Journal of Materials Science 16: 5395-5429.

9. Khan G, Kim YK, Choi SK, Han DS, Abdel-Wahab A, et al. (2013) Evaluating the catalytic effects of carbon materials on the photocatalytic reduction and oxidation reactions of $\mathrm{TiO}_{2}$. Bull Korean Chem Soc.
10. Sarbajit Banerjee and Stanislaus S Wong (2002) Functionalization of carbon nanotubes with a metal-containing molecular complex. American Chemical Society 2: 49-53.

11. Feng Y, Zhang H, Hou Y, McNicholas TP, Yuan D, et al. (2008) Room temperature purification of few-walled carbon nanotubes with high yield. ACS Nano 2: 1634-1638. [Crossref]

12. Yu WX, Sheng JY, Hong Z, Chang ZJ (2011) Methanol oxidation over TiO2-modified multi-walled carbon nanotubes supported Pt-Mo electrocatalyst. Chem Rer Chinese Universities 27: 486-489.

13. Das R, Eaqub Ali Md, Bee Abd Hamid S, Annuar MSM, Ramakrishna S (2014) Common wet chemical agents for purifying multiwalled carbon nanotubes. Journal of Nanomaterials.

14. Grujicic M, Gao G, Rao AM, Tritt TM, Nayak S (2003) UV-light enhanced oxidation of carbon nanotubes. Appl Surf Sci 214: 289-303.

15. Tsang SC, Harris PJ, Green ML (1993) Thinning and opening of carbon nanotubes by oxidation using carbon dioxide. Nature 362: 520-522.

16. Yuin Chia JS, Michelle TT, Tan JK, Chin PS, Khiew, et al. (2012) A Parametric study on the synthesis of graphene using Piranha-like thermal exfoliation, IPCBEE.

17. Ziegler KJ1, Gu Z, Peng H, Flor EL, Hauge RH, et al. (2005) Controlled oxidative cutting of single-walled carbon nanotubes. J Am Chem Soc 127: 1541-1547. [Crossref]

18. Datsyuk V, Kalyva M, Papagelis K, Parthenios J, Tasis D, et al. (2008) Chemical oxidation of multiwalled carbon nanotubes. Carbon 46: 833-840.

19. Rasel Das, Md. Eaqub Ali, Sharifah Bee Abd Hamid, MSM Annuar, et al. (2014) Common wet chemical agents for purifying multiwalled carbon nanotubes, hindawi publishing corporation Journal of Nanomaterials.

20. Kim YJ, Shin TS, Choi HD, Kwon JH, Chung YC, et al. (2005) Electrical conductivity of chemically modified multiwalled carbon nanotube/epoxy composites. Carbon 43 23-30.

21. Firas H, Abdulrazzak, Falah H Hussein (2015) Effects of nanoparticle size on catalytic and photocatalytic activity of carbon nanotubes-titanium dioxide composites. $J$ Environ Anal Chem 2: 2

22. Nishimura K, Okazaki N, Pan L, Nakayama Y (2004) In situ study of iron catalysts for carbon nanotube growth using X-ray diffraction analysis. Japanese Journal of Applied Physics 43: 471-474.

23. Capula S, Aguir K, Cervantes F, Villa L, Moncayo JA, et al. (2014) Ozone sensing based on palladium decorated carbon nanotubes. Sensors: 6806-6818

24. Ashcroft, Neil W, Mermin ND (1976) Solid State Physics. New York: Holt, Rinehart and Winston.

25. Manoj B, Kunjomana AG (2012) Study of stacking structure of amorphous carbon by X-ray diffraction technique. Int J Electrochem Sci 7: 3127-3134.

26. Leroy A, Harold PK (1950) Determination of crystallite size with the X-ray spectrometer. J App Phys 21: 126-7.

27. Datsyuk V, Kalyva M, Papagelis K, Parthenios J, Tasis D, et al. (2008) Chemical oxidation of multiwalled carbon nanotubes. Carbon 46: 833-840.

28. Quaroni L, Reglinski J, Smith W (1995) Surface enhanced resonance Raman scattering from cyanocobalamin and 5'-deoxyadenosylcobalamin. J Raman Spect 26: 1075-1076.

29. Ying Y, Jimmy C Y, Cho-Yin C, Yan-Ke C, Jin-Cai Z, et al. (2005) Applied catalysis B: Environmental 611

Copyright: (C2016 Al Mgheer T. This is an open-access article distributed under the terms of the Creative Commons Attribution License, which permits unrestricted use, distribution, and reproduction in any medium, provided the original author and source are credited. 